\title{
Experimental Research on Multiple Wire Electrode Electrochemical Micro Machining
}

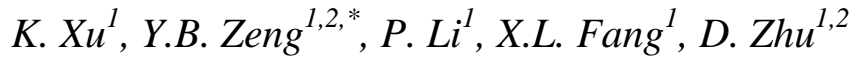 \\ ${ }^{1}$ College of Mechanical and Electrical Engineering, Nanjing University of Aeronautics and \\ Astronautics, Nanjing, China, 210016 \\ ${ }^{2}$ Jiangsu Key Laboratory of Precision and Micro-Manufacturing Technology, Nanjing, China, 210016 \\ *E-mail: binyz@nuaa.edu.cn
}

doi: 10.20964/2016.07.65

Received: 7 April 2016 / Accepted: 15 May 2016 / Published: 4 June 2016

\begin{abstract}
Wire electrochemical micro machining is potentially a useful method in the fabrication of metal micro parts or devices with high aspect ratios and high surface quality. However, because the material removal rate is slow, a long machining time is required to produce the micro products. To increase productivity, the use of multiple wire electrodes is introduced, and an electrochemical cell model of multiple wire electrodes built. It is proved theoretically and experimentally that the overall machining efficiency can be increased by using multiple wire electrodes, but that it does not increase linearly with the number of wire electrodes. To obtain the optimal pulse conditions for stable machining, changes in the average slit width and the uniformity of the slit width using three wire electrodes, according to the applied pulse voltage, pulse on-time, pulse period and feed rate, are investigated. Finally, with three wire electrodes, micro structures are successfully machined on $80-\mu \mathrm{m}$-thick cobalt-base elastic alloy under optimal conditions.
\end{abstract}

Keywords: Multiple wire electrodes; Machining efficiency; Slit width; Uniformity

\section{FULL TEXT}

(C) 2016 The Authors. Published by ESG (www.electrochemsci.org). This article is an open access article distributed under the terms and conditions of the Creative Commons Attribution license (http://creativecommons.org/licenses/by/4.0/). 